\title{
Competency Development in Distributed Work Environments
}

\author{
Pamela Meil and Eckhard Heidling \\ Institute for Social Science Research (ISF), Jakob-Klar-Strasse 9, D-80796 Munich, \\ Germany. \\ Email: pamela.meil@isf-muenchen.de
}

\begin{abstract}
New company strategies are characterised by fluid company boundaries in which the integration of production and service processes take place outside of its borders. These open structures lead to increasing forms of distributed work, often organised into projects. This paper examines the shift in competency requirements associated with distributed work, and the individual and organisational measures that are necessary to assure their development and retention.
\end{abstract}

Key words: Geographically distributed work, Competency requirements, Critical situations, Experienced-based learning

\section{INTRODUCTION}

Today stringent customer demands, accelerated time-to-market schedules, and high levels of quality have put companies under pressure to adapt and modernise their product development processes. The ability to succeed over the long term on global markets depends in large part on keeping up with dynamic and constantly changing conditions. One way to meet these challenges is the organisation of product development and production processes in cooperative, often international, company networks which can react flexibly to new developments on the market. A central characteristic of this new type of work organisation can be seen in the increasing appearance of forms of "distributed work". Distributed work can be understood as the organisation of work across tasks, process chains, or production/service networks. In distributed work, employees from different departments, sites, and 
often countries, cooperate on a single task, a chain of tasks, or a network of tasks. One of the most important forms that distributed work takes is cooperation in temporary project teams, often supported by the use of modern information technologies. (DiMAGGIO 2001)

A number of new dimensions enter the work process under conditions of distributed work which require companies to organise the creation and transfer of know-how and competencies differently. The question arises as to how to develop competencies necessary for international project work, how to bind them together with existing skills, and how to use them effectively in processes of product development. These issues were examined in 3 companies from the automobile, aerospace and automobile supplier industries, which all organise their development processes in distributed project work. Based on research undertaken at these companies during recent years, this paper addresses following three issues:

1. how competency requirements have shifted as a result of distributed work, and which new competencies are necessary to carry out international project work;

2. what new demands are placed on the project participants and especially the project leaders in the framework of distributed work; and the difficulties involved in developing the appropriate competencies in existing organisational contexts;

3. recommendations for a new content and organisation for the development of distributed work competencies.

\section{NEW COMPETENCY REQUIREMENTS IN DISTRIBUTED WORK}

Distributed work is characterised by its complexity. New work situations, broadly defined tasks, changing actors and social frameworks - all in a limited time frame - make up the world of distributed work. Considering the contrast to traditional company-bound forms of work, it becomes clear that in such open work processes, a wide range of new demands arise for the work content and the competence development of engineers and other skilled workers.

In these forms of distributed work one of the major challenges is to utilise all of the competencies that are available in a process chain or a production or service network. There are two difficult aspects to this challenge: One is the shift in both the intensity and diversity of competencies that are required for distributed work environments. The other is activating very different types of competencies at different phases of the process. 


\subsection{Shifts in Intensity}

Interviews in the 3 companies in our study revealed that a shift in competency requirements had occurred in a number of dimensions for project work in engineering and development. Table 1 lists five different dimensions of competency categories. The left hand column gives examples of the expectations for engineers that were characteristic of the organisational structures for product development prevalent up to now. The right hand column shows the shifts in intensity in competency dimensions that have taken place as a result of distributed work organised in international projects.

In the technical dimension, there continues to be a demand for high levels of technical expertise. However, what is changing is the additional requirement for system integration and monitoring the contributions from partners. This means that there is a need for a much broader range of technical knowhow outside of individual specialties, or even company boundaries. In the area of communication, the competency shift involves the ability to prioritise and filter large amounts of information to focus on the most significant parts. Also required is a more far-reaching coordination and understanding across fields, as well as the ability to negotiate, sometimes in conflicting situations.

Organisational competence in the era of distributed work reveals a growing complexity for work plans and work packages as well as increased difficulty in putting teams together to carry out the work plans. Project leaders are responsible for their project result and progress, but they have no authority in the traditional line organisations and hierarchies that still exist in companies. Therefore to organise the capacities they need, they often have to engage in quite a bit of convincing and diplomacy. Interview partners referred to the process of acquiring a team to organise the work as „horse trading." This term describes the informality as well as the difficulty involved in getting the capacity necessary to carry out work plans. This type of team formation presents a real challenge for the everyday work of project leaders in distributed work.

Particularly in the area of management competence, the project participants, and especially the project leaders, have experienced a large shift and intensification of their competence profile. Generally speaking, distributed work makes it necessary for project leaders to make decisions, take responsibility for fulfilling goals, and for disciplining project members much more autonomously than before. At the same time, this leadership role and risk taking is expected without the corresponding authority of hierarchical position. Thus formalised or ritualised procedures are thus replaced by informal interactions and more instinctual behaviours. 
Table 1. Shifts in Competence Intensity

\begin{tabular}{|l|l|}
\hline \multicolumn{1}{|c|}{ Traditional } & \multicolumn{1}{|c|}{ Technical Dimension } \\
\hline \multicolumn{2}{|c|}{ Communication Dimension } \\
\hline $\begin{array}{l}\text { Coordination and execution of inner } \\
\text { company processes }\end{array}$ & $\begin{array}{l}\text { Inter-company system integration; } \\
\text { monitoring partner contributions }\end{array}$ \\
\hline \multicolumn{2}{|c|}{ Organisation Dimension } \\
\hline $\begin{array}{l}\text { Formal Documentation; } \\
\text { Consultation inside company }\end{array}$ & $\begin{array}{l}\text { Prioritising material for overview; } \\
\text { Consultation between companies }\end{array}$ \\
\hline Customer presentations & Media competence \\
\hline \multicolumn{2}{|c|}{ Management Dimension } \\
\hline $\begin{array}{l}\text { Design and formulation of work } \\
\text { packages }\end{array}$ & $\begin{array}{l}\text { Design and formulation of complex } \\
\text { work packages }\end{array}$ \\
\hline Team construction & $\begin{array}{l}\text { Team construction under tight } \\
\text { personnel availability }\end{array}$ \\
\hline \multicolumn{2}{|c|}{ Intercultural Dimension } \\
\hline $\begin{array}{l}\text { Heightened time and cost pressures } \\
\text { teams }\end{array}$ \\
\hline $\begin{array}{l}\text { Technically oriented international } \\
\text { exchange }\end{array}$ & $\begin{array}{l}\text { Intensive exchange beyond the } \\
\text { technical dimension }\end{array}$ \\
\hline Limited number of actors & Diverse actors \\
\hline & $\begin{array}{l}\text { Long and more frequent foreign } \\
\text { assignments }\end{array}$ \\
\hline $\begin{array}{l}\text { Monitor work content; Competence } \\
\text { to evaluate work as basis for } \\
\text { decision-making }\end{array}$ & Monitor work content and costs \\
\hline & $\begin{array}{l}\text { Ability to assert oneself in conflict } \\
\text { situations; Conflict resolution; Risk } \\
\text { taking }\end{array}$ \\
\hline & Leadership without hierarchy \\
\hline
\end{tabular}

Finally, more intercultural competence is demanded in distributed work processes. This does not mean merely learning the habits and qualities of other nationalities as broad generalities. For distributed work, a shift and increase in intercultural competence means having openness and flexibility in interactions taking place at the level of the work process and dealing with 
the varying bodies of knowledge and experiential backgrounds as well as the occupational and cultural differences that make up the cooperative base of distributed work. What emerges is an understanding that finding solutions to problems is not only an objective process, but also a negotiated one.

In effect, the intensification of international cooperative work leads to an interaction of different company and occupational structures which creates the need for the development of new working and social identities, at least in the context and duration of the work project. In order to carry out the diverse tasks embedded in project work, the participants, and in particular the project leader, has to find a way to manage and use the distributed competencies found among the employees.

\subsection{Shifts in Diversity}

Related to this point, one of the most challenging aspects of distributed work, particularly in a leadership position, is being able to activate different types of competencies in the various phases of a project at the appropriate time. (see Figure 1) To demonstrate what is involved in activating the competencies demanded in distributed work environments, it is necessary to look at the product development process more closely, in particular the various phases that a project passes through from the conceptual phase to the start of production.

Figure 1 show, from the example of a typical car development process that different stages in a project phase correspond to diverse demands for competency needs. At the beginning of a project, the participants shape and form the work process; they are in an exploratory phase. In this phase, the project group is engaged in a process of discovery and thus openness, flexibility, and creativity are called for. As the boundaries for the division of labour and delivery get fixed, a process of negotiation begins. At this second stage, the project leader is called upon to build a consensus, evaluate the various actors in the group, and attain a fair and effective distribution of resources. For all of the project members, there is a need to know when and how to compromise, while simultaneously recognising and representing company interests and constraints. In this framework, project participants have to find a basis for negotiating which brings them both closer to their goal while at the same time representing their particular interests. When particularly difficult problems arise or when negotiations break down, mediation is necessary. For the project leader, this requires the competency to resolve conflicts and keep the members goal-oriented. In the course of the project, a number of assumptions or plans will need revision. Given the very strong orientation in the adjustment stage often leads to critical situations. The project leader needs to have the ability to deal with changes and find 
new solutions. The final stages of the project involve a certain amount of consolidation of the project's many parts. This requires the competency to be goal-oriented, see the complete picture, think in process terms and obtain high performance levels from project participants under extreme time pressure. Finally, problems solving is required during most of the project's running time. In project organisation, it is the participants who have to be in a position to make intelligent and timely decisions even in cases where information or data is incomplete, contradictory, or communication is conflicting (HINDS, KIESLER 2002).

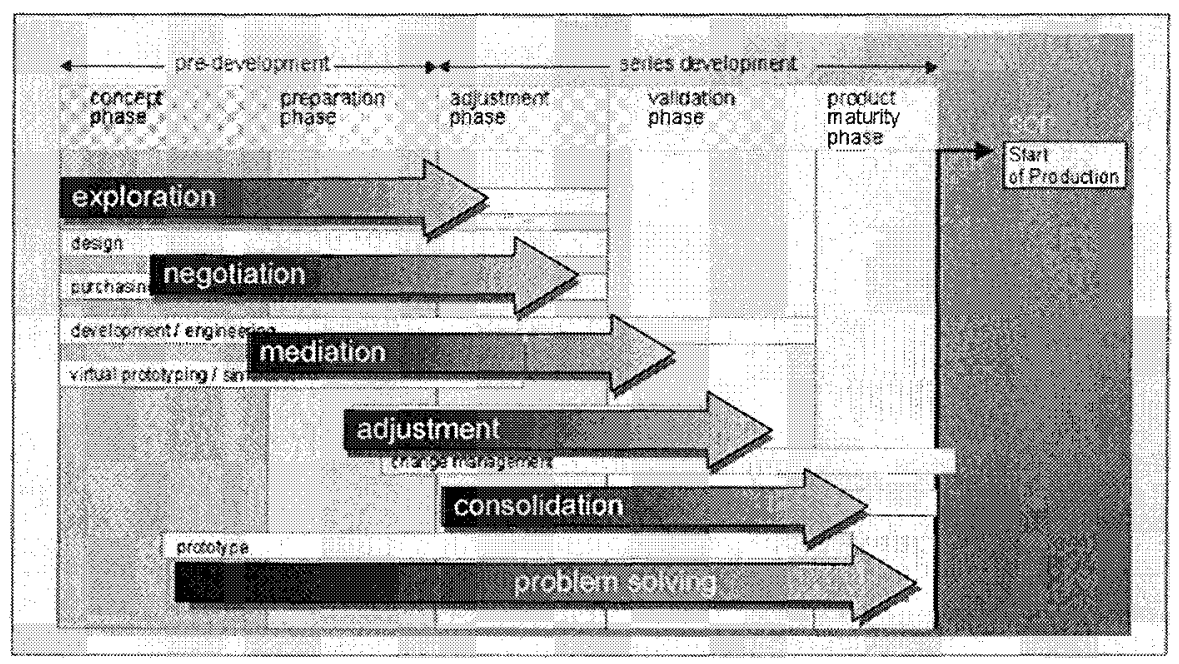

Figure 1. Product phases and competency needs

\section{COMPETENCIES BEYOND BOUNDARIES}

An important factor related to new forms of distributed work is how knowledge gets generated and transferred. Knowledge is created in concrete, spatially bounded learning contexts and work processes. The implementation of knowledge, however, takes place in different spaces, both within and across company contexts. This leads to a complex interaction between knowledge production tied to a particular place and the exchange of results which takes place across large distances. Out of this situation, a fundamental tension arises in which competencies are generated over a long period in territorially and socially embedded systems, but are used and exchanged in temporally limited and spatially disparate dimensions that go way beyond 
company boundaries. Projects have a key role in this exchange process, because they represent the links between the inside and outside. Thus, projects become the pool where newly reintegrated, quasi-connected pieces of knowledge come together. In this way, project participants take on an important linking function in regulating knowledge and information flows between the different company sites (HEIDLING et al. 2004).

\subsection{Opening the Container Model}

One of the difficulties for competency development in processes of distributed work is that the traditional way in which skills are acquired and experience is developed occurs in a "closed" space (MEIL 2000). Highly skilled employees are products of nationally-based institutions of training and further training where they acquire their formal skills and specific areas of expertise. Then, the continued development of knowledge takes place within the company, usually within hierarchically organised functional departments. We call this form of competency development the "container model" (see Figure 2).

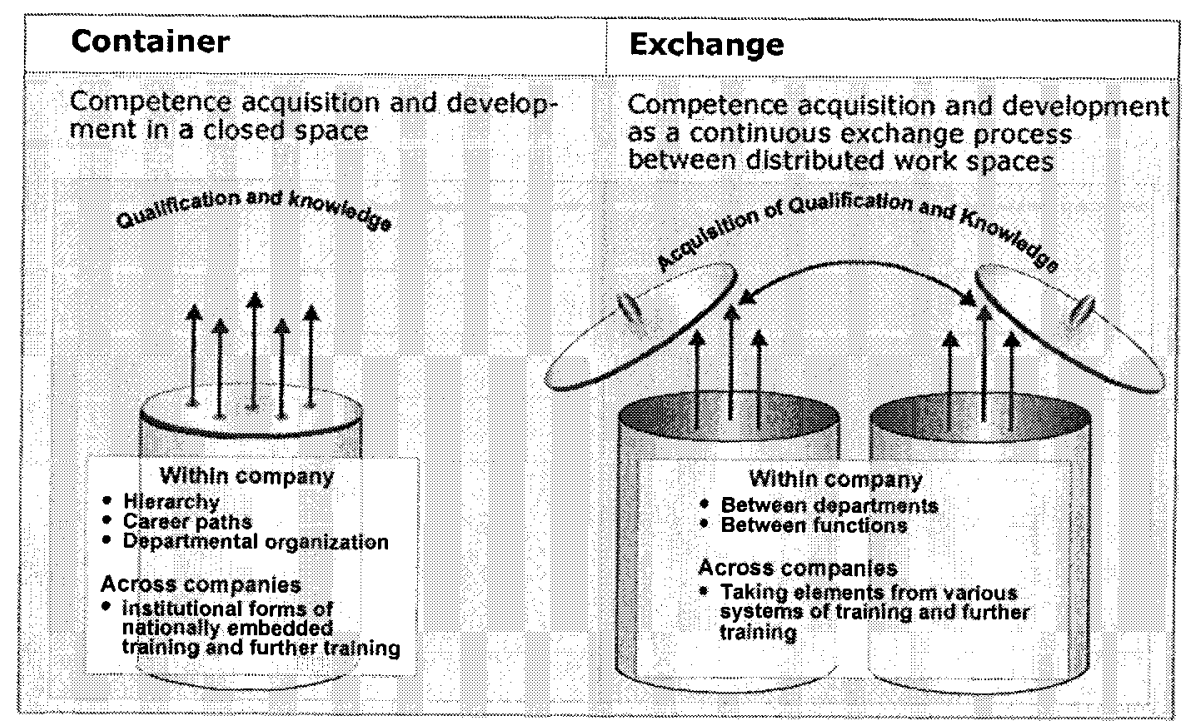

Figure 2. Container model of competency acquisition

(Source: MEIL, HEIDLING 2003, p. 182)

The way knowledge is generated in this closed system can be counterproductive for the requirements that face skilled workers and engineers in processes of distributed work. In distributed work processes, competence acquisition and development is a continuous process of exchange between 
departments and functional areas within companies. Across companies, it entails the exchange between different training traditions, cultural backgrounds and working habits. Therefore, the type of expertise and experience acquired in container type organisational structures does not provide the appropriate preparation for the dynamic, conflict-laden, broad-based knowledge and experience necessary in distributed work contexts.

\subsection{Operating in Unclear Situations}

Another critical aspect of operating in distributed work is the integration of different working styles, creating a new basis for interaction (BRANNEN, SALK 2000). In a project, new actors from different companies or departments, often with different cultural and training backgrounds, have to come together, and within a fixed period of time, have to complete something. "Normal" forms of hierarchy or authority do not exist in these systems, and the process can get very complicated due to the complexity of the products, and also due to conflicting interests. However, it should also be recognised that conflict is not the only medium of exchange, since the overall goal of the participants is basically the same and the technical basis for understanding is also the same. Thus, the interaction is characterised by a simultaneity of conflict and cooperation as well as power relations that can be both symmetric (for instance, in terms of hierarchical level), and asymmetric (for instance between customers such as automobile producers or airplane manufacturers and their suppliers). The actors working in distributed work processes have to learn to deal with these contradictory elements of interaction. At the same time, trust is an important component of the relationship in project groups as is the certainty that each member takes responsibility for his/her part of the process, especially the project leader who is responsible for ensuring that the project moves forward as a whole.

The complex network in which development and innovation processes take place in distributed work create their own dynamic and make it impossible to calculate and plan a priori all contingencies in a top-down manner. (BÖHLE, MEIL 2003) Moreover, recognising the source of a problem is no guarantee that it can be avoided. It is more important to create conditions which allow an interactive understanding for carrying out tasks along the process chain. Especially as a result of missing information and incomplete data, the employees themselves have to be in a position to make timely and informed decisions on their own. In these open and dynamic work processes, an entire set of new demands arise for the competence profile of the employees. One increasingly important demand lies in being able to act effectively in unclear situations. 
When an incidence arises that deviates from pre-determined plans or problems occur that fall outside the boundary of eventuality, the situation in the development or production process moves from being typical or foreseeable to critical. Critical situations have a variety of causes ranging from external risks (last minute changes from the customer) to poor internal communication (contradictory priorities) or incomplete information (vague contractual details), problems of communication or leadership, or the unwillingness to try new solutions. For distributed work processes, critical situations occur so often that they take on a degree of normality. The company representatives expressed it such that: "critical situations are almost the norm - it is basically typical to have a critical situation."

Naturally, companies use every means at their disposal to learn from previous critical situations in order to plan better and take steps to prevent them (ANTONACOPOULOU 2002). Given that critical situations are often viewed as the outcome of a lack of clarity in the specifications that are provided, the response is frequently to employ technical tools and models to plan the control process to an even greater level of detail. Yet, despite a relatively sophisticated range of planning tools and models, and large financial investments in this process, the results are less than satisfactory. Especially in projects where innovative or new developments are involved, unplanned and critical situations arise frequently, and it can be precisely the wrong approach to try to plan in greater detail and leave less autonomy to the work process. Rather than preventing critical situations, this approach can have the undesired result of hindering inventive solutions. What is generally missed in purely technical orientations is the need to improve the experience and learning base of the project participants and particularly the project leader to deal with critical situations and to be oriented to constructive problem solving. This might sound trivial. However, the approaches that would apply to this type of learning contradict with strongly embedded views concerning planning against unforeseen contingencies as a solution, and a purely scientific-logical approach to problems and problem-solving (BÖHLE 2002).

\section{RECOMMENDATIONS FOR DEVELOPING DISTRIBUTED WORK COMPETENCIES}

\subsection{Contents for Distributed Work Qualifications}

Besides the usual technical expertise and "soft skills" (such as communication and cooperation) that are included in the training packages in compa- 
nies today, there are three additional aspects that need to be considered to work effectively in a distributed work environment.

a) Mediation and negotiation: A fundamental problem at the centre of distributed work projects is that actors represent different departments or companies and therefore in certain situations have conflicting interests. When a technical product or problem the object of interaction is, it can easily seem that the grounds for discussion are neutral and the solution technically mediated. This can obscure the conflict that is surrounding the problem. Project leaders have to learn how to manage conflict and contradictory demands for interaction. The goal is to balance different interests and roles and to keep sight of a common end result while recognising the potential and source for conflict. Normal training trajectories and job experience do not prepare project leaders for this task.

b) Process competence: Process competence is a central element in distributed work because it is necessary for the acquisition and utilisation of knowledge and experience in interdisciplinary, inter-company and international work processes. Process competence guarantees that the various working steps and tasks of the various actors lead to the coherent development or construction of an end product. Naturally, given the extreme complexity of development processes, which are increasingly organised in inter-company process chains, the expectations for the project participants to have an overview and understanding of the entire process grow accordingly. An extremely important aspect for development work, which is highly conceptual, is the ability to make mental images of projects and processes. Project participants from various companies are responsible for one piece of a much larger product, whether it be a car or an airplane. They not only have to be in a position to envision the steps of development of their piece, but they have to foresee the integration of their piece in the total product. Thus, an important aspect of distributed work revolves around anticipation and openness, in contrast to more categorical and formalised ways of thinking. Openness is especially significant for distributed work because of the variety of different perspectives and ways of thinking that exist in a project group, and because the development process is not linear, but rather processoriented. Anticipation is important because the end results can be years away from steps taken at a given time, steps that are nonetheless critical to the final result. Having process competence encompasses the ability to create analogies to past practice and experience, envisioning, in an abstract sense, steps to development, foreseeing the integration of the pieces into a total product or process, and being able to anticipate end results. 
c) Negotiated culture: When working in distributed work environments, the working situation is characterised by its heterogeneity. Project participants or those feeding results into the project come, at the minimum, from different departments, and very often from different companies and different countries and therefore cultures. Through the interaction in mixed groups, new work identities emerge. To facilitate this process, the project leader has to achieve a common ground of compromise and understanding, open the project to create new experience spaces and develop a framework in which all group members are involved in a process of innovation. The openness and flexibility that this requires and the amount of negotiation, as opposed to the setting of objective criteria that is involved, is highly underestimated.

\subsection{Instruments}

One of the main messages of this paper is that the competencies necessary for distributed work processes are not effectively transmitted in existing training programs, embedded as they are in national and internal company contexts. Furthermore, the recognition that distributed work is highly complex and displays a large number of critical situations, has led to the unfruitful conclusion that only technical solutions and more planning can master the work process. The position here, however, is that it is precisely the subjective orientation and experience-based approach to work that has to be strengthened to carry out distributed project work, especially in the areas of development and engineering. Two instruments are needed to promote the type of competency development called for in distributed work: experiencebased learning methods and an appropriate organisational framework to accumulate project work know-how.

Experience based learning methods possess the following characteristics:

1. They allow experience gathering.

2. They promote problem-solving.

3. They induce process competence and associative thinking.

4. They make it possible to learn from mistakes (without hurting company interests).

All of these components have to derive from learning methods or tools which stay close to the actual product development process and that are found in project structured distributed work environments. The tools can be scenarios, simulations, games, or self-organised learning methods. Important is that they are developed out of and linked to real work experiences. The more abstractly conceptualised the tools are, the less effective they will be. 
The second pillar for accumulating work project know-how is an organisational framework that:

1. Creates career paths that are geared to accumulate experience and process competence.

2. Gives project leaders back-up support from superiors when negotiation processes require it.

3. Establishes forums for experience exchange and the opportunity (and time) to participate in them.

\section{CONCLUDING REMARKS}

For forms of distributed work to be effective, it is necessary to utilise the entire range of competencies that are available in a value chain or network of production or service processes. This involves designing the right kind of cooperation processes between individual employees or groups, who come from differing occupational and cultural traditions. It also involves generating qualifications which allow the development of a comprehensive "process" competence. The new competence profiles of project participants, and in particular project leaders, encompass the ability to negotiate, to react effectively in critical situations, and to create the basis for the emergence of new work identities. Thus, distributed work entails decisive challenges for company organisation and qualification, and requires new methods and instruments for the generation and maintenance of competencies.

\section{REFERENCES}

ANTONACOPOULOU, T.:

Time and reflexivity in Organisation Studies.

In: Organisation Studies,

Berlin, 23(2002)6, pp. 857-862.

BÖHLE, Fritz:

Vom Objekt zum gespaltenen Subjekt.

In: Subjektivierung von Arbeit.

Edts.: MOLDASCHL, Manfred; VOSS, Günter.

München, Mering: Hampp Verlag, 2002, pp. 101-133.

BÖHLE, F., MEIL, P.:

Das Unplanbare bewältigen.

In: Tagungsband der Fachtagung "Projektmanagement in Seiten des Wandels".

Eds.: BUTS, C.; PAPESCH, G.; WILHELMS, G.

Augsburg: Universität Augsburg, 2003, pp. 36-47. 
BRANNEN, Mary; SALK, Jane:

Partnering across borders: Negotiating organizational culture in a German-Japanese joint venture.

In: Human Relations,

Thousand Oaks, CA, 53(2000)4, pp. 451-487.

DiMAGGIO, P.:

Introduction: Making Sense of the Contemporary Firm and Prefiguring Its Future.

In: The Twenty-First-Century Firm.

Ed.: DiMAGGIO, P.

Princeton, Oxford: Princeton University Press, 2001, pp. 3-30.

HEIDLING, E.; MEIL, P.; ROSE, H.:

Neue Anforderungen an Kompetensen erfahrungsgeleiteten Arbeitens und selbstgesteuerten Lernens bei industriellen Fachkräften unter Bedingungen verteilter Arbeit.

In: Bewältigung des Unplanbaren.

Eds.: BÖHLE, F.; SEVSAY-TEGELHOFF, N.

Wiesbaden: Westdeutscher Verlag, 2004. In print.

HINDS, P.; KIESLER, S. (eds.):

Distributed Work.

Cambridge, MA: The MIT Press, 2002.

MEIL, Pamela:

Blick über die Grenze - View across Borders: Approaches for Meeting New Demands for

Skill in Different National Contexts.

In: Industrielle Fachkräfte für das 21. Jahrhundert.

Edts.: LUTZ, Burkart; MEIL, Pamela; WIENER, Bettina,

Frankfurt/M., New York, NY: Campus Verlag, 2000, pp. 129-157.

MEIL, Pamela; HEIDLING, Eckhard:

Competency Development in Distributed Work Environments.

In: Human Aspects in Production Management.

Eds.: ZÜLCH, Gert; STOWASSER, Sascha; JAGDEV, Harinder S.

Aachen: Shaker Verlag, 2003, pp. 180-186.

(esim - European Series in Industrial Management, Volume 5) 